IJ§ER

ISSN: 2149-5939
International Journal of Social Sciences and Education Research

Online, http://dergipark.gov.tr/ijsser

Volume: 3(2), 2017

\title{
Vatandaşların E-Belediyecilik hizmetlerinden yararlanma düzeyi: İzmit belediyesi örneği
}

\author{
The utilization level of the citizens from E-Municipality services: The example of \\ Izmit municipality
}

Demokaan Demirel1

\begin{abstract}
Received Date: $01 / 09$ / 2016
Accepted Date: 15 / $01 / 2017$

$\ddot{O} z$

Vatandaşlar bilgi toplumunda kamu kurumları ile sürekli bir iletişsim içindedir. Kamu hizmetlerinde etkinliği săglama amaçlı e-devlet ve e-belediyecilik uygulamaları dünya genelinde yaygınlık kazanmıştır. Belediyeler, kent sakinlerine uygar ve kaliteli yaşam olanakları sunmak zorundadır. Ayrıca şeffaf yönetimin bir gereği olarak ürettiği bilgileri kamuoyuyla paylaşmak durumundadır. E-belediyecilik anlayıșılla belediyeler; bilgiye dayal, vatandaşların katıldı̆̆ sağlıklı hizmet sunma arayışına girmişlerdir. Bu bakımdan internet, vatandaşlar ile yerel yönetimler arasinda iletişim kurmada kullanılabilecek en etkin yöntemlerden biridir. Bu çalışmada e-devlet ve e-belediye kavramları ele alınmakta ve İzmit Belediyesi'nce yürütülen e-belediyecilik uygulamaları yapılan bir anket aracıllğglyla değerlendirilmektedir. Çalışmanın amacl; vatandaşların eğitim, gelir düzeyi, yaş ve meslek gruplarına göre İzmit Belediyesi'nin sunmakta olduğu e-belediyecilik hizmetlerinden yararlanma düzeylerini tespit etmektir.
\end{abstract}

Anahtar Sözcükler: E-devlet, E-belediye, bilgi teknolojileri, kent bilgi sistemi, İzmit belediyesi.

\begin{abstract}
Citizens are continuously in interactive communication with public institutions. Todays, e-government and e-municipality practices, promising more effective and efficient public services, become widespread throughout the world. The municipalities are obliged to provide civilized and quality of life facilities to the citizens. Also, as a requirement of transparent management, they have to share with the public being produced by them. The municipalities seeking to provide healthy services which are based on information participated in the citizens. Therefore, Internet is one of the most effective methods that can be used to communicate between local governments and citizens. In this study, the concepts of e-government and e-municipality are discussed and e-municipality applications of Izmit Municipality are examined through a survey. The aim of this study evaluates utilization level of the citizens in which offered e-municipality services by the İmit Municipality according to education, income, age, and professional groups.
\end{abstract}

Keywords: E-government, E-Municipality, information technologies, city information system, İmit Municipality.

\section{Giriş}

Günümüz devletleri bilgi ve iletişim teknolojilerinden etkin bir biçimde yararlanmayı amaçlamaktadır. Özellikle kamu harcamalarındaki artışların vergilerle tam anlamıyla karşılanamaması, kamu yönetimindeki yozlaşma ve etik dışı uygulamalardaki artış, kamu hizmetlerinin verimli ve etkin bir kaynak kullanımıyla sunulamaması e-devletin kamusal alandaki önemini arttırmıştır. Edevlet; devletin toplum nezdindeki imajını pozitif yönde değiştirmeyi amaçlayan idare ile vatandaşlar arasındaki karşılıklı ilişkileri güçlendiren önemli araçlardan biridir. Kamu kurumlarının e-

${ }^{1}$ Yrd. Doç. Dr., Ömer Halisdemir Üniversitesi, Kamu Yönetimi Bölümü, Niğde Türkiye, demokaand@gmail.com 
Demirel, D. (2017). Vatandaşların E-Belediyecilik hizmetlerinden yararlanma düzeyi: İzmit belediyesi örneği. International Journal of Social Sciences and Education Research, 3(2), 411-424.

devlet yapılanmasına geçişle birlikte teknik fonksiyonlarının ön plana çıktığı görülmektedir. Teknokrat sınıfın kamu politikalarının şekillendirilmesi ve uygulamada karşılaşılan olası sorunların çözümüne yönelik katkıları giderek artmaktadır. E-devletin yerel düzeydeki yansıması olan belediyecilik; belediyenin faaliyetlerinin sanal ortama taşınmasıyla birlikte kaynak kullanımında tasarruf sağlamaktadır ve bürokratik nitelik taşıyan işlemleri hızlandırmaktadır. Yönetsel kararların vatandaş erişimine açılmasıyla birlikte idari hesap verebilirlik temin edilmektedir. Vatandaşların gerekli bilgi ve belgelere erişiminin sağlanması demokratik siyasal katılımın bir ön koşulu olarak yönetimde açıklığı araçsallaştırmaktadır. Bu çalışmanın amacı; İzmit Belediyesi'nin sunmakta olduğu e-belediyecilik hizmetlerinden vatandaşların yararlanma düzeylerini eğitim, gelir, yaş ve meslek gruplarına göre değerlendirmektir. Çalışmada e-belediye hizmetlerinden yararlanma oranıyla katılımcıların demografik özellikleri arasında anlamlı bir farklılık olup olmadığına ilişkin hipotezler Tek Yönlü Anova ve Ki-Kare bağımsızlık testleri aracılı̆̆ıyla sinanarak elde edilen veriler istatistiki açıdan yorumlanmıştır. Çalışmada öncelikle e-devlet ve e-belediye kavramları incelenmekte, ardından İzmit Belediyesi sınırlarında tesadüfi örneklem yöntemine göre yapılan alan araştırmasının sonuçları değerlendirilmektedir.

\section{E-Devlet ve E-Belediye kavramları}

E-Devlet, kamu hizmetlerinin bilgi ve iletişim teknolojilerinden yararlanılarak etkileşimli bir biçimde çoklu kanallar üzerinden yurttaşlara, özel sektöre ve kamu kurum ve kuruluşlarına sunulmasıdır (Çelikkol, 2008: 25). E-devletin kamu yönetimi reform programlarında üzerinde önemle durulan bir konu haline gelmesinde kamu ve özel sektör arasındaki ortakların giderek artmas1, özel sektör şirketleri, sivil toplum kuruluşları, araştırma enstitüleri arasında artan işbirliği, şirketler arası iş ortaklarının önem kazanması ile nihai olarak kamu hizmetinin sunulduğu vatandaşların ihtiyaç duydukları bilgiye aracısız olarak kendilerinin erişmesi etkili olmuştur (Chidurala ve diğerleri; 2001: 11). Teknolojik değişim, iletişimin ve bilgisayarlaşmanın hızını ve hacmini büyük ölçüde arttırarak zaman ve mekân kavramlarını derinden sarsmıştır. Aynı zamanda kamusal karar verme sürecine kitlesel erişimi sağlamıştır (Pollitt, 2011: 380). Buna paralel bir biçimde vatandaşların yönetim kurumlarına yönelik talepleri çeşitlenerek hizmetin kaliteli sunumu yönündeki beklentileri artmıştır. Vatandaşlara yüksek kalitede bir hizmet sunumunu gerçekleştirmek adına e-devlet; yönetsel işlevleri ve süreçleri yeniden yapılandırmayı, kamu yönetiminde koordinasyon ve işbirliğinin önündeki engelleri ortadan kaldırmayı, idari performansı yükselterek idare ile yurttaşlar arasındaki ilişkileri geliştirmeyi kendisine amaç edinmiştir (Yıldırım, 2010: 3). Modern bilgi teknolojileri daha bireysel tarzda hizmet sunma olanağ getirirken; hizmet maliyetlerini azaltmakta, personel alımını kolaylaştırmakta, yüksek işsizliğin olduğu alanlarda istihdamı geliştirmekte ve kamu personeline daha kaliteli bir yaşam tarzı sunmaktadır. Tek duraklı kamu kurumları ve ağdaki tek pencereli yapılar yeni kamu görevleri oluşturmaktadır. Farklı alanlardan gelen kamu görevlilerini bir araya getirmekte, önceden ayrı olan faaliyetleri standartlaştırarak koordine etmektedir. Örgütsel sınırları aşan yetenekler gerektirdiği için e-devlet yapılanması yüksek düzeyde eğitim ve yetiştirme programına tabi personel ihtiyacını da arttırmaktadır. Bu durumda kamu yönetimindeki her bir meslek tamamen kurmay kadrolardaki uzmanlara daha bağımlı hale gelmekte, daha hızlı ve daha iyinin yanı sıra daha ucuz kamu hizmeti sunumu önem kazanmaktadır (Pollitt, 2011: 388). E-devletin rahat, kolay, hızlı ve etkin hizmet sunumunu gerçekleştirmesi devlet ile toplum arasında daha iyi ilişkilerin inşa edilmesine de yardımcı olmaktadır. Çünkü; kamuda bilgi teknolojilerinin kullanımına yönelik politik yaklaşım kamusal taleplerin karşılanmasını, bürokrasinin dışsal politik makamlara hesap vermesini ve kolektif çıkarların 
Demirel, D. (2017). The utilization level of the citizens from E-Municipality services: The example of İzmit municipality. International Journal of Social Sciences and Education Research, 3(2), 411-424.

temsil edilmesini sağlamaktadır. Vatandaşın yönetsel süreçlere katılımı kamu kurumlarının internet siteleri aracılığıyla teşvik edilmektedir (Maan, ve diğerleri, 2014: 10-11).

E-devlet yapılanmasının başarıya ulaşması üzerinde etkili olan bazı faktörler şunlardır (Naralan, 2008: 460-463):

- Gelişmişlik Faktörü: Devletin e-hizmetler sunabilmesi için gerekli kaynaklara sahip olmasının yanı sıra kullanıcılarında sunulan hizmetlere ulaşabilecek bir donanıma sahip olmaları ekonomik güç ve gelişmişlikle yakından ilgilidir.

- Yönetim Faktörü: Devletin ekonomik planda etkin rol oynadığı "devletçi” ülkelerde kamu kaynaklarının devlet kontrolünde olması nedeniyle vatandaşların devletten alacağı hizmet sayısı oldukça fazladır. Bu durumda devletin e-hizmetlerde etkin bir rol oynaması gerekirken aksine devletçi ülkelerde e-devletin gelişimi oldukça yavaştır.

- Kurumsal Yapı Faktörü: E-devlet hizmeti verebilecek kurumların hantal yapıda olması, bürokratik işlemlerin fazlalı̆̆ e-devlete geçişin önündeki engellerdir.

- Teknik Altyapı Faktörü: Vatandaşların e-devlet hizmeti alabilmeleri için iletişim aracı ve iletişim kanalı şeklindeki iki temel unsur teknik altyapı kapsamında değerlendirilir. E-devlet hizmetlerinden yararlanabilmek için etkin bir iletişim aracı ile iletişim kanalına birlikte sahip olmak gereklidir.

- Beşeri Altyapı Faktörü: E-devlet bilgi sistemlerinin kurulması ve kullanılması için eğitimli ve yeterli donanıma sahip yetişmiş insan gücü gereklidir. Nitelikli insan gücü uygulamada yürütülen faaliyetlerin başarı şansını arttıracaktır.

- E-Devlet Portalı Faktörü: E-devlet portalı kullanıcılarının alabilecekleri e-devlet hizmetlerini bir arada bulundurur. Ayrıca kullanıcılara e-hizmetleri sunmasının yanında yeni e-hizmetlerden yararlanmaları konusunda yönlendirmelerde bulunur.

E-devletin aracı olarak e-hizmet; vatandaş-hizmeti tedarik eden arasındaki ilişkiyi güçlendirme amacına dönük örgütsel süreç ve teknolojilerle bütünleşmiş ve müşteri tarafından yönlendirilen internet temelli, interaktif bir içeriğe sahip hizmetleri tanımlar (de Ruyter ve diğerleri, 2001). Aşağıdan yukarı doğru e-hizmet; e-tedarik ve arz zinciri işlevlerini içerir. Yukarıdan aşağıya doğru ise e-hizmet; Vatandaş-müşteri ilişkileri yönetimini, vatandaş/müşteri taleplerinin dikkate alınmasını gerektirir (Ancarani, 2005: 8). E-hizmet, daha çok artan rekabet ve müşteri beklentilerine ilişkindir. Bu bakımdan bilgi ve iletişim teknolojileri odaklı hizmetler sunan kamu kurumlarının vatandaş ve/veya müşteri perspektifine göre örgütsel performanslarını geliştirmelerini gerekli kılar (O, Neill ve diğerleri, 2001).

E-devlet hizmetlerinin vatandaşların katılımıyla anlam kazanacağ 1 yaklaşımı yerel yönetimlerin yatay koordinasyonunu mümkün kılan yapısı ve doğrudan vatandaşların ihtiyaç ve beklentilerine yönelik hizmet işleviyle daha kolay bir biçimde örtüşmektedir (Uçkan, 2003: 295). E-devlet kamu yönetimini vatandaş taleplerine göre etkin ve hızlı bir biçimde faaliyetlerini sürdürme yönünde şekillendirecek araçlardan biridir. Yönetimde açıklığı temin etmek amacıyla radikal olarak kamu kurumlarında örgütsel düzeyde demokratikleşmenin ana unsurlarının işlevsellik kazanmasına kamuoyunun ihtiyaçlarını göz önüne alarak hizmet eder.

E-belediye e-devletin önemli bir parçasıdır. E-belediye uygulamaları; elektronik olarak alınan kararların paylaşımını hızlı ve seri bir elektronik süreci, hizmetlerin tedarik edilmesinde yerel halkın tavsiye ve dileklerinin göz önüne alınmasını, kurumlar arasında etkin iletişimi, bireysel 
Demirel, D. (2017). Vatandaşların E-Belediyecilik hizmetlerinden yararlanma düzeyi: İzmit belediyesi örneği. International Journal of Social Sciences and Education Research, 3(2), 411-424.

katılım ve performans ölçümlerini dikkate almaktadır (Yargovan, 2013: 21). Vatandaş ve belediyeler arasındaki yakınlık nedeniyle belediyeler e-katılımı kolaylıkla sağlayabilir.

E-belediyeciliğin yararları şöyle sıralanabilir (Polat ve diğerleri, 2013: 387):

- Bürokratik yazışmaları bilgiye dönüştürüp kâğıt masrafını azalmak

- $\quad$ Örgüt içi telefon görüşmeleri azaltmak, elektronik iletişimi mümkün kılmak

- Belediye başkanı ve belediye örgütünün performansı hakkında vatandaşların görüş ve alışverişinde bulunmasını sağlamak.

- İnternet aracılığıyla kurumsal yenilenmeyi temin etmek

- SSehre ilişkin olaylar ve belediyelerle ilgili aktiviteler hakkında güncel bilgi vermek

- Vatandaşlar e-belediyecilik uygulamalarıyla su, doğalgaz, vergi vb. borçlarını öğrenerek fatura ve vergi ödemesini elektronik ortamdan yapabilmektedir. Özellikle çevrim içi fatura ve vergi tahsilatı ile ilgililer belediyeye gelmeden işlemleri gerçekleştirebilmekte, böylece zamandan da tasarruf sağlamış olmaktadır (Gürler Hazman, 2005: 66-67).

E-belediyecilik; kente ilişkin tüm verilerin bilgi ve iletişim teknolojileriyle destekli çalışmalarla yönetilerek kent ve toplum yararına yönelik bilgilerin üretilmesi ve halkın hizmetine sunulmasıdır (Bengshir ve Akay, 2006: 33). E-belediye ile yönetsel süreçlerin daha ileri bir değişime uğraması, yerel halk ile etkileşime geçme, örgütlerde yeniden düzenleme ve değişimin sağlanması, yerel hizmetleri daha iyi, daha az maliyetli ve daha ulaşılabilir hale getirmek, yerel demokrasinin başlaması ve gelişmesini sağlamayı hedeflemektedir (Yıldırım ve Öner, 2004: 53).

Aşağıdaki tabloda geleneksel yerel yönetim anlayışı ile e-belediyecilik karşılaştırılmaktadır.

Tablo 1. Geleneksel yerel yönetim anlayışı ve E-Belediyecilik

\begin{tabular}{|c|c|}
\hline Geleneksel Yerel Yönetim Anlayışı & E-belediyecilik \\
\hline Paylaş1lmayan idari kararlar & Alınan kararları elektronik ortamda paylaşma \\
\hline Uzun bürokratik iş akışı & Hızlı ve elektronik süreç \\
\hline $\begin{array}{c}\text { Halka ilişkin kararların yöneticiler tarafından veril- } \\
\text { mesi }\end{array}$ & $\begin{array}{c}\text { Yerel halkın dilek ve önerilerinin değerlendiril- } \\
\text { mesi }\end{array}$ \\
\hline Yönetim-vatandaş ilişkisi & Hizmet sunan-müşteri ilişkisi \\
\hline Yetkili birimlere başvuru sürecinin zorluğu & Erişilebilirlik ve sürekli gelişme \\
\hline Uzun bürokratik süreçler & Kurumlar arası entegrasyon ve etkinlik \\
\hline Bürokratik denetim & Bireysel katılım ve performans ölçümleri \\
\hline
\end{tabular}

Kaynak: Henden ve Henden, 2005: 56.

E-belediyeciliğe geçiş süreci çeşitli aşamalardan geçilmesini gerektirmektedir. İlk aşamada; enformasyon sağlayan portallar kullanıma sokulmalıdır. İkinci aşama, vatandaşlar, girişimciler ve ticari kurumlar, iş görenler için verilen hizmetler ve sertifikalandırma hizmetlerini sunan portalların kullanıma açılmasıdır. Üçüncü aşamada; kamu hizmetlerinin görülmesi ve vatandaş kat1lımının arttırılması için yerel bir sivil ağ oluşturulması söz konusudur. Böylece aynı bölgede oturan ve ortak nitelikte hizmet beklentisi içinde bulunan vatandaşların birbiriyle iletişime geçebilmesi, ihtiyaçların ve bunların niteliklerinin belirlenebilmesi, belediyenin yönlendirici danışmanlığından yararlanma yoluyla vatandaşların kendi içinde bir platform oluşturmasının sağlanması amaçlanır. Son aşamada; vatandaş-yönetim ilişkilerini geliştirmeyi amaçlayan bir e-posta platformu ve sanal tartışma forumlarının yürürlüğe konulmasıyla belediye ve vatandaşların her biri arasında kısa süre içinde sonuçlanabilen bir etkileşim süreci oluşturulur (Anselmi ve diğerleri, 2002). 
Demirel, D. (2017). The utilization level of the citizens from E-Municipality services: The example of İzmit municipality. International Journal of Social Sciences and Education Research, 3(2), 411-424.

E-belediyecilik sürecinde kullanılması gerekli araçlar ise şunlardır (Şat, 2008: 221-235):

Bilgi Sistemleri: Kent bilgisi, kente ilişkin su havzalarından, kentin sınırlarına, nüfus hareketlerinden yapılara, katı atıklardan park ve bahçelere kadar uzanan geniş yelpazedeki bilgileri ifade eder. E-belediyeciliğin sağlıklı bir biçimde işleyebilmesi için gerekli ortamın oluşturulması ve yasal düzenlemelere uygun yapıların kurulması kent bilgi sistemleri gibi karar destek sistemlerinin oluşturulmasını gerektirir. Hızla büyüyen ve gelişen kentlerde insanların gereksinimlerini en iyi ekonomik koşullarda arz etmeleri ve plânlamalarına yönelik yatırım ve hizmetlerin gerçekleşmesi için bilgi sistemleri kentleşmeyi kontrol altına alır (Akman ve Okçu, 2013: 758). Bu bakımdan coğrafi bilgi sistemleri, belediyelerin e-belediyeye dönüşmelerinde özellikle harita, kadastro, imar uygulama işlemleri, şehir ve bölge planlama, teknik altyapı hizmetleri, peyzaj planlama ve yönetimi, imar, yapı, ruhsat, fen işleri, kentsel yönetim ve denetim, kriz yönetimi gibi alanlarda vazgeçilmez bir araçtır (Bengshir ve Akay, 2006: 33).

Belediye Ağ Sayfası: E-belediyenin başarısı için saydam, kullanımın kolay olduğu, güvenli bir ağ sayfası hayati bir önemdedir. Bu konuda iki türlü yaklaşım söz konusudur: Bilgi odaklı yaklaşım; kent bütçesi, demografik bilgiler, yerel faaliyetlerin takvimi, önemli turistik cazibe merkezleri, rehber, basın bültenleri ve iş olanakları gibi konularda çok miktarda bilgiyi içeren tek duraklı hizmet sunumunu ön plana çıkarmaktadır. Kullanıcı odaklı portal tasarımında ise; farklı kullanıcı gruplarının gereksinimlerine göre ağ üzerindeki bilgi ve hizmetler sınıflandırılmaktadır (Ho ve Tat, 2002: 434-444). Kullanıcı odaklı ve arka planında e-çalışan varlığa dayalı siteler e-kapı olarak değerlendirilmektedir. E-kapıda kullanıcıyı ihtiyacına göre daha ayrıntılı bilgiye taşıyacak önemli hizmetlerin listesi öncelikle sunulmaktadır (Şat, 2008: 232).

Belediye düzleminde internete taşınma; belediye içi mali, personel, yazı işleri, imar plânlaması vb. yönetim süreçlerinin otomasyonu, kentte yaşayanların şikâyet, istek ve görüş bildirimleri ile belediyeden işyeri açma, proje onaylatma gibi ruhsat, izin alma ve onay başvurularının belediye tarafından tahsil edilen yasal ödemelerin internet üzerinden yapılması ve yerel yönetime ilişkin temel veri ve bilgilerin diğer kamu kurum ve kuruluşlarıyla bağlantılandırılarak paylaşılmasını gerektirmektedir (Güler, 2001: 6, www.inet.tr.org.tr).

Belediyenin Kablosuz Hizmet Sunma Uygulamaları (WAP): Kablosuz hizmetler, mobil telefonlar, avuç içi bilgisayarlar gibi mobil iletişim araçları üzerinde internet içeriği sağlayan bir teknolojidir. Bu hizmetlerle cep telefonundan belediyedeki bilgilere çevrim içi erişim mümkündür. Böylece vergi borcu sorgulaması yapmak isteyen, hizmet masalarında veya belediyedeki birimlerde işleri devam eden vatandaşlar işlemlerinin hangi aşamada olduğunu belediyeye gitmeden rahatlıkla takip edebilmektedir (Şat, 2008: 234-235).

E-belediye uygulamalarında başarı sağlamak için vatandaş ilişkileri yönetimi ve hizmette etkinlik göstergelerinin oluşturulması, elektronik ortama aktarılacak yeni hizmet alanlarının geliştirilmesi, stratejik iç ve dış paydaşların, vatandaşların, diğer yerel, ulusal veya uluslararası kamu kurum ve kuruluşlarla proje, tedarik, değer zincirine daha esnek ve güvenli şekilde entegre olması, mobil bilgi alışverişleri için gerekli kurumsal altyapıların oluşturularak kurumsal bir performans yönetim sisteminin kurulması gereklidir (Postacı ve Ayhan, 2013: 9). Ayrica, e-belediye proje ve uygulamaları bütüncül ve bilgi paylaşımını esas alan bir anlayışla koordine edilmeli, bu uygulamaların hayata geçirilmesi için gerekli temel veri tabanları, ortak altyapı ve hizmetler geliştirilerek çeşitli kanallardan bütünleşik hizmet sunumu sağlanmalı, kullanıcı odaklılık, kullanıcı memnuniyeti, kişisel bilgi mahremiyeti, bilgi güvenliği, katılımcılık ve şeffaflık gözetilmelidir (DPT, 2010: 54). 
Demirel, D. (2017). Vatandaşların E-Belediyecilik hizmetlerinden yararlanma düzeyi: İzmit belediyesi örneği. International Journal of Social Sciences and Education Research, 3(2), 411-424.

\section{3. İzmit Belediyesi’nde E-Belediyecilik uygulamaları}

Türkiye'de e-belediyeleşme süreci oldukça yakın bir geçmişe sahiptir. 1989 yılında TODAİE (Türkiye Orta Doğu Amme İdaresi Enstitüsü) bünyesinde Yerel Yönetimler Araştırma ve Eğitim Merkezi'nin kurulmasıyla birlikte yerel yönetimler portalı olarak adlandırılan ve yerel yönetimlerin buluştuğu Yerelnet Ağı oluşturulmuştur. Yerel yönetim mevzuatının, belediye hizmet kılavuzunun ve ihale ilanlarının yer aldığı portal 01.01.2001 itibarıyla "yerelnet. org.tr" adıyla uygulamaya geçmiştir. İçişleri Bakanlığı Mahalli İdareler Genel Müdürlüğü’nün internet üzerinden yerel yönetimler ile merkezi yönetim arasındaki veri alışverişini sağlamak için bir veri tabanına sahip olmak amacryla hazırladığı Yerel Bilgi Projesi yerel yönetim birimlerinin diğer birimlerle olan ilişkilerini internete taşımıştır (Nohutçu ve Demirel, 2005: 46).

İzmit Belediyesi'nin e-belediyecilik hizmetleri incelendiğinde, vatandaşlar ile karşılıklı iletişimi güçlendirmeye yönelik uygulamaların bulunduğu gözlemlenmektedir. Online vize uygulaması ile vatandaşlar beyan bilgileri ile sicil, tahakkuk ve tahsilat bilgilerini sorgulayabilmektedir. E-imar uygulaması, arsa rayiç değerlerinin sorgulanmasını sağlamaktadır. Süper hizmet masası, vatandaşların dilek ve şikâyetlerine yönelik olarak oluşturulmuştur. Vatandaşlar siteden bilgi edinme başvurusunda da bulunabilmektedir. Başkan'a Mektup kısmından belediye faaliyetlerine yönelik talepler, vatandaşların yerel hizmetlerle ilgili sorunları doğrudan belediye başkanına iletilmektedir. İZMEK ise; belediyenin meslek edindirme kurslarına yönelik faaliyetleriyle ilgili bilgiler sunmaktadır.

\subsection{Araştırmanın amacı ve metodolojisi}

Araştırma kapsamında incelenen İzmit Belediyesi'nin nüfusu 2014 Belediye seçimlerine göre 212088 olarak saptanmıştır. $\% 95$ güven düzeyinde $\pm \% 5$ hata payı gözetilmek suretiyle anket çalışması tespit edilen örneklem büyüklüğü olan 384 kişiye doğrudan uygulanmıştır. Araştırmanın amac1; İzmit Belediyesi'nin sunmakta olduğu e-hizmetler hakkında yerel halkın bilgi sahip olup olmadığını, sunulan hizmetlerin hangilerinden yararlandığı ve sunulan e-hizmetleri ne derece başarılı bulduklarını saptamaktır. Çalışmada tesadüfi örneklem yöntemi kullanılmış, veriler bilgisayar ortamında SPSS 22.0 programı kullanılarak Tek Yönlü Anova ve Ki-Kare Bağımsızlık Testi uygulanarak değerlendirilmiştir.

Tablo 2. Katılımciların profilleri

\begin{tabular}{|l|l|l|l|}
\hline \multirow{5}{*}{ Cinsiyet } & & Frekans & Yüzde \\
\cline { 2 - 4 } & Erkek & 178 & 46,35 \\
\cline { 2 - 4 } & Bayan & 206 & 53,37 \\
\hline \multirow{5}{*}{ Yaş } & $18-25$ & 37 & 13,77 \\
\cline { 2 - 4 } & $26-35$ & 56 & 16,10 \\
\cline { 2 - 4 } & $36-45$ & 107 & 27,86 \\
\cline { 2 - 4 } & $46-55$ & 93 & 24,22 \\
\cline { 2 - 4 } & $56+$ & 91 & 23,58 \\
\hline \multirow{5}{*}{ Ĕgitim } & İlköğretim & 36 & 9,38 \\
\cline { 2 - 4 } & Lise & 87 & 22,54 \\
\cline { 2 - 4 } & Önlisans & 87 & 22,54 \\
\cline { 2 - 4 } & Lisans & 137 & 35,49 \\
\cline { 2 - 4 } & Lisansüstü & 37 & 9,59 \\
\hline & $0-1000 \mathrm{t}$ & 23 & 5,99 \\
\cline { 2 - 4 } & $1001-2000 \mathrm{t}$ & 73 & 19,01 \\
\cline { 2 - 4 } & $2001-3000 \mathrm{t}$ & 105 & 27,34 \\
\hline & 3001 ve üstü & 183 & 47,66 \\
\hline
\end{tabular}


Demirel, D. (2017). The utilization level of the citizens from E-Municipality services: The example of İzmit municipality. International Journal of Social Sciences and Education Research, 3(2), 411-424.

Yukarıdaki tabloda görüldüğü üzere, ankete katılan kadın sayısı $(\% 53,37)$ erkeklere oranla $(\% 46,35)$ daha fazladır. Katılımcıların çoğunluğu 36-45 yaş aralığındadır $(\% 27,86)$. Ankete katılanların genel anlamda eğitim düzeyi de yüksektir. Çoğu lisans düzeyinde bir eğitim almıştır $(\% 35,49)$. Katılımcılar mesleki açıdan daha çok işçi statüsündedir $(\% 29,95)$. Katılımcıların çoğunun gelir düzeyi 3000 t'nin üzerindedir $(\% 47,66)$.

Tablo 3.Vatandaşların E-hizmetlerden yararlanma düzeyi

\begin{tabular}{|c|c|c|}
\hline & Sıklık & \% \\
\hline Online Vezne & 60 & 15,63 \\
\hline E-İmar & 65 & 16,93 \\
\hline Süper Hizmet Masası & 36 & 9,38 \\
\hline Bilgi Edinme Başvurusu & 56 & 14,58 \\
\hline Başkana Mektup & 64 & 16,67 \\
\hline İzmek & 24 & 6,25 \\
\hline
\end{tabular}

Katılımcıların İzmit Belediyesi'nin sunmakta olduğu e-hizmetlerden yararlanma düzeyleri birbirlerine oldukça yakındır. Süper hizmet masası ve İzmek (İzmit Meslek Edindirme Kursları) gibi e-hizmetlerden diğerlerine göre yararlanma düzeyi daha düşüktür.

Tablo 4. E-Hizmetleri başarılı bulma düzeyi

\begin{tabular}{|c|c|c|}
\hline & Sıklık & $\mathbf{\%}$ \\
\hline E-Hizmetleri Başarılı Buluyorum & 292 & 76,04 \\
\hline E-Hizmetleri Başarılı Bulmuyorum & 33 & 8,59 \\
\hline Fikrim Yok & 59 & 15,36 \\
\hline
\end{tabular}

Anket katılımcılarının büyük bir çoğunluğu belediye tarafından sunulan e-hizmetlerin başarılı olduğunu belirtmiştir $(\% 76,04)$. Hizmetleri başarılı bulmayanların yüzdesi ise oldukça düşüktür $(\% 8,59)$.

Tablo 5. İnternetten E-hizmet sunmanın faydaları

\begin{tabular}{|c|c|c|}
\hline & Sıklık & \% \\
\hline Ucuz-Kaliteli Hizmet Sunumu & 78 & 20,31 \\
\hline Etkin ve Verimli Kaynak Kullanımı & 88 & 22,92 \\
\hline Bilişim Toplumu Oluşumuna Yaptığı Katkı & 112 & 29,17 \\
\hline $\begin{array}{c}\text { Hesap Verebilirliği ve Demokratikleşmeyi Sağ- } \\
\text { lama }\end{array}$ & 106 & 27,60 \\
\hline
\end{tabular}

Vatandaşlara internet aracıllğııla belediyenin e-hizmetleri sunmasının ne gibi yararları olduğu sorulmuştur. Elde edilen sonuçlara göre; vatandaşlar daha çok e-hizmetler aracıllğıyla internet ve bilgi teknolojileri kullanımının artacağını bunun da bilişim toplumuna dönüşüm yönünde önemli bir adım olduğunu belirtmişlerdir $(\% 29,17)$. Buna ilaveten e-hizmetlerin belediye yönetiminde demokratikleşmeyi arttıracağ 1 ve hesap verebilirliği temin edeceğini düşünenlerin oranı da oldukça yüksektir $(\% 27,60)$.

E-belediye hizmetlerinden yararlanma düzeyiyle yaş arasında anlamlı bir farklılık olup olmadığını ölçmek amacıyla bağımsız örneklem $\mathrm{T}$ testi ve Ki-kare bağımsızlık testi uygulanmış ve iki hipotez geliştirilmiştir:

$H_{0:}$ E-belediye hizmetlerinden yararlanma ile katılımcıların yaş düzeyleri arasında anlamlı bir farklillk yoktur.

$H_{I}$ : E-belediye hizmetlerinden yararlanma ile katılımcıların yaş düzeyleri arasında anlamlı bir farklılık vardır. 
Demirel, D. (2017). Vatandaşların E-Belediyecilik hizmetlerinden yararlanma düzeyi: İzmit belediyesi örneği. International Journal of Social Sciences and Education Research, 3(2), 411-424.

Ki-Kare bağımsızlık testi

\begin{tabular}{|c|c|c|c|}
\hline İstatistik & Değer & Serbestlik derecesi & Anlamlılık düzeyi \\
\hline Pearson Chi-Square & 239,69 & 24 &, 000 \\
\hline
\end{tabular}

Tablo 6. E-belediye hizmetleri ve yaşa göre yararlanma

\begin{tabular}{|l|l|l|l|l|l|}
\hline E-Belediye Hizmetleri & \multicolumn{5}{|c|}{ Yaş Aralı̆̆ } \\
\hline & $\mathbf{1 8 - 2 5}$ & $\mathbf{2 6 - 3 5}$ & $\mathbf{3 6 - 4 5}$ & $\mathbf{4 6 - 5 5}$ & $\mathbf{5 6 +}$ \\
\hline Online Vezne & $\% 1,67$ & $\% 40$ & $\% 46,67$ & $\% 10$ & $\% 1,67$ \\
\hline E-İmar & $\% 0$ & $\% 15,38$ & $\% 27,69$ & $\% 33,85$ & $\% 23,08$ \\
\hline Süper Hizmet Masası & $\% 0$ & $\% 2,78$ & $\% 55,56$ & $\% 41,67$ & $\% 0$ \\
\hline Bilgi Edinme Başvurusu & $\% 7,14$ & $\% 17,86$ & $\% 32,14$ & $\% 35,17$ & $\% 7,14$ \\
\hline Başkana Mektup & $\% 6,25$ & $\% 12,50$ & $\% 12,50$ & $\% 3,13$ & $\% 65,63$ \\
\hline İzmek & $\% 12,50$ & $\% 0$ & $\% 0$ & $\% 33,33$ & $\% 54,17$ \\
\hline Hizmet Almayanlar & $\% 31,65$ & $\% 3,80$ & $\% 18,99$ & $\% 25,32$ & $\% 20,25$ \\
\hline
\end{tabular}

Tablodan da görüleceği üzere; yaşa göre e-belediye hizmetlerinde yararlanma düzeyi oldukça farklılaşmaktadır. P değerinin Sig. 0,000<0,05 çıkması bunu kanıtlamaktadır. E-belediyecilik hizmetlerinden daha çok $36-45$ yaş grubu $(\% 27,86)$ ile $46-55$ yaş grubu $(\% 24,22)$ ve 56 yaş üzeri $(\% 23,70)$ yararlanırken en az $18-25$ yaş aralığı e-hizmet almaktadır. $(\% 9,64)$. Bu durumda $\mathrm{H}_{0}$ hipotezi reddedilmektedir.

Tablo 7. E-Belediyecilik hizmetlerinden yararlanma ve gelir düzeyi

\begin{tabular}{|c|c|c|c|c|}
\hline E-belediyecilik hizmetleri & \multicolumn{4}{|c|}{ Gelir düzeyleri } \\
\hline & $\mathbf{0 - 1 0 0 0 t}$ & $\mathbf{1 0 0 1 - 2 0 0 0 t}$ & $\mathbf{2 0 0 1 - 3 0 0 0 t}$ & $\mathbf{3 0 0 1}$ ve üstü \\
\hline Online Vezne & $\% 0$ & $\% 55$ & $\% 10$ & $\% 35$ \\
\hline E-İmar & $\% 0$ & $\% 9,23$ & $\% 15,38$ & $\% \mathbf{0} 3,38$ \\
\hline Süper Hizmet Masas1 & $\% 0$ & $\% 2,78$ & $\% 19,44$ & $\% 77,78$ \\
\hline Bilgi Edinme Başvurusu & $\% 0$ & $\% 33,93$ & $\% 21,43$ & $\% 44,64$ \\
\hline Başkana Mektup & $\% 0$ & $\% 7,81$ & $\% 22,13$ & $\% 64,16$ \\
\hline İzmek & $\% 0$ & $\% 0$ & $\% 62,50$ & $\% 37,50$ \\
\hline Hizmet Almayanlar & $\% 29,11$ & $\% 11,39$ & $\% 46,84$ & $\% 12,66$ \\
\hline
\end{tabular}

Ki-Kare bağımsızlık testi

\begin{tabular}{|c|c|c|c|}
\hline İstatistik & Değer & Serbestlik derecesi & Anlamlılı düzeyi \\
\hline Pearson Chi-Square & 232,97 & 18 &, 000 \\
\hline
\end{tabular}

E-belediye hizmetlerinden yararlanma ile gelir düzeyi arasındaki ilişkiyi tespit etmek için iki hipotez oluşturulmuştur:

$H_{0}$ : E-belediye hizmetlerinden yararlanma ile gelir düzeyi arasında anlamlı bir farklllık yoktur.

$H_{1}$ : E-belediye hizmetlerinden yararlanma ile gelir düzeyi arasında anlamlı bir farklıllk vardır.

Tablodan da görüldüğü üzere Ki-Kare testi sonucunda Sig. Değeri, $000<0,05$ olduğu için vatandaşların gelir düzeylerine göre e-belediye hizmetlerinden yararlanma durumu anlamlı bir farklılık göstermekte ve $\mathrm{H}_{0}$ hipotezi reddedilmektedir. Gelir düzeyi 0-1000t arası olanların e-belediyecilik hizmetlerinden yararlanma oranı oldukça düşüktür $(\% 5,99)$. Gelir düzeyi $3000 \mathrm{t}$ ve üstü olanların e-hizmetlerden yararlanma oranı $(\% 47,66)$ oldukça yüksektir. Bu durum düşük gelir gruplarının ehizmetlerden yararlanmaları hususunda sosyal belediyecilik uygulamaları kapsamında desteklenmeleri gerektiğine işaret etmektedir. 
Demirel, D. (2017). The utilization level of the citizens from E-Municipality services: The example of İzmit municipality. International Journal of Social Sciences and Education Research, 3(2), 411-424.

Tablo 8. E-Belediye hizmetlerinden yararlanma ve meslek grupları

\begin{tabular}{|c|c|c|c|c|c|c|c|}
\hline E-belediye Hizmetleri & \multicolumn{7}{|c|}{ Meslek Grupları } \\
\hline & Memur & İş̧i & Esnaf & Ŏğrenci & Emekli & Serbest Meslek & Isşsiz \\
\hline Online Vezne & $\% 40$ & $\% 1,67$ & $\% 33,33$ & $\% 8,33$ & $\% 0$ & $\% 16,67$ & $\% 0$ \\
\hline E-İmar & $\% 9,23$ & $\% 38,46$ & $\% 0$ & $\% 1,54$ & $\% 0$ & $\% 50,77$ & $\% 0$ \\
\hline Süper Hizmet Masas1 & $\% 58,33$ & $\% 38,89$ & $\% 0$ & $\% 2,78$ & $\% 0$ & $\% 0$ & $\% 0$ \\
\hline Bilgi Edinme Başvurusu & $\% 3,57$ & $\% 69,64$ & $\% 12,50$ & $\% 7,14$ & $\% 7,14$ & $\% 0$ & $\% 0$ \\
\hline Başkana Mektup & $\% 13$ & $\% 15$ & $\% 0$ & $\% 8$ & $\% 13$ & $\% 15$ & $\% 0$ \\
\hline İzmek & $\% 0$ & $\% 37.50$ & $\% 0$ & $\% 0$ & $\% 45,83$ & $\% 16,67$ & $\% 0$ \\
\hline
\end{tabular}

Ki-Kare bağımsızlık testi

\begin{tabular}{|c|c|c|c|}
\hline İstatistik & Değer & Serbestlik derecesi & Anlamlılık düzeyi \\
\hline Pearson Chi-Square & 345,08 & 36 &, 000 \\
\hline
\end{tabular}

Meslek grupları ile e-belediye hizmetlerinden yararlanma arasında bir ilişki olup olmadığını test etmek için iki hipotez geliştirilmiştir:

$H_{0}$ : Meslek gruplarl ile e-hizmetlerden yararlanma arasında anlamlı bir farklılık yoktur.

$H_{1}$ : Meslek gruplarıyla e-hizmetlerden yararlanma arasında anlamlı bir farklıllk vardır.

Tablodan da görüldüğü üzere; Pearson Ki-Kare testi sonucunda p değeri $0,00<0,05$ olduğu için meslek gruplarına göre e-belediyecilik hizmetlerinden yararlanma düzeyi farklılık göstermektedir. $\mathrm{Bu}$ durumda $\mathrm{H}_{0}$ hipotezi reddedilir. Meslek grupları içinde e-belediye hizmetlerinden en çok yararlanan kesim işçiler ile serbest meslek gruplarıdır. İşçiler \%29,95 düzeyinde, serbest meslek grupları ise $\% 21,88$ oranında e-hizmet alırken bu iki grubu memurlar $(\% 17,71)$ takip etmektedir. Herhangi bir işi bulunmayanlar ise e-hizmet almamaktadır. Ankete katılanlardan işçiler daha çok bilgi edinme başvurusunu $(\% 69,64)$, serbest meslek mensupları e-imar uygulamasını $(\% 50,77)$, emekliler ise İzmek meslek edindirme kursları uygulamasını $(\% 45,83)$ kullanmaktadır.

Son olarak, e-belediye hizmetlerinden yararlanmanın eğitim düzeylerine göre farklılık gösterip göstermediğini saptamak amacıyla Tek Yönlü Anova testi uygulanmış ve iki hipotez geliştirilmiştir:

$H_{0}$ : E-belediye hizmetlerinden yararlanmayla eğitim düzeyi arasında anlamlı bir farklllık yoktur.

$H_{1}$ : E-belediye hizmetlerinden yararlanmayla eğitim düzeyi arasında anlamlı bir farklılık vardır.

Tablo 9. E-belediyecilik hizmetlerinden yararlanma ve eğitim düzeyi

\begin{tabular}{|c|c|c|}
\hline Eğitim Düzeyi & \multicolumn{2}{|c|}{ E-Belediye Hizmetlerinden Yararlanma } \\
\hline & Ssklık & $\mathbf{\%}$ \\
\hline İlköğretim & 36 & 9,37 \\
\hline Lise & 87 & 22,65 \\
\hline Önlisans & 87 & 22,65 \\
\hline Lisans & 137 & 35,67 \\
\hline Lisansüstü & 37 & 9,63 \\
\hline
\end{tabular}


Demirel, D. (2017). Vatandaşların E-Belediyecilik hizmetlerinden yararlanma düzeyi: İzmit belediyesi örneği. International Journal of Social Sciences and Education Research, 3(2), 411-424.

Homojenlik testi

\begin{tabular}{|l|l|l|l|l|}
\hline & Levene Statistic & df1 & df2 & Anlamlılık \\
\hline E-Belediye Hizmetlerinden Yararlanma & 22,09 & 4 & 379 &, 000 \\
\hline
\end{tabular}

\begin{tabular}{|c|c|c|c|c|c|c|}
\hline \multirow{2}{*}{$\begin{array}{c}\text { E-Belediye Hizmet- } \\
\text { lerinden Eğitim } \\
\text { Durumuna Göre } \\
\text { Yararlanma }\end{array}$} & $\begin{array}{c}\text { Karelerin top- } \\
\text { lamı }\end{array}$ & $\begin{array}{c}\text { Serbestlik de- } \\
\text { recesi }\end{array}$ & $\begin{array}{c}\text { Ortalama ka- } \\
\text { rekök }\end{array}$ & F değeri & $\begin{array}{c}\text { Sig. (Anlamll- } \\
\text { llk) }\end{array}$ \\
\cline { 2 - 7 } & $\begin{array}{c}\text { İki grup ara- } \\
\text { sinda }\end{array}$ & 389,66 & 4 & 97,41 & 35,66 &, 000 \\
\cline { 2 - 7 } & $\begin{array}{c}\text { Grupların } \\
\text { kendi ara- } \\
\text { sinda }\end{array}$ & 1035,30 & 379 & 2,73 & & \\
\cline { 2 - 7 } & Toplam & 1424,96 & 383 & & & \\
\hline
\end{tabular}

Tabloya bakıldığında; lise (\%22,65), ön lisans $(22,65)$ ve lisans ve lisansüstü $(45,3)$ mezunlarının e-belediyecilik hizmetlerinden daha yoğun bir biçimde e-belediyecilik hizmetlerinden yararlandıkları gözlemlenmektedir. İlköğretim mezunlarının e-belediyecilik hizmetlerinden yararlanma oranı ise diğer gruplara göre oldukça düşüktür $(\% 9,37)$. Tek yönlü Anova ve gruplar arası homojenlik testinin sonucunda açığa çıkan anlamlılık değeri Sig. $000<0,05$ olduğu için varyansların değişken olduğu ve kendi aralarında farklılık gösterdiği saptanmıştır. Bu durumda $\mathrm{H}_{0}$ hipotezi reddedilir.

\section{Sonuç}

Sanayi toplumunu ekonomik, sosyal, kültürel ve siyasal açıdan dönüştüren e-devlet ile birlikte bilgi üretiminin ve sektörünün, beşeri sermaye faktörünün, iletişim teknolojilerinin ve eğitimde niteliğin önem kazandığı yeni bir devlet anlayışı ortaya çıkmıştır. E-devlet yeni bir yönetim anlayış1 olarak devletin hılı, etkin ve verimli bir biçimde çalışmasını, kurumlar arası bilgi alışverişinin sağlanmasıyla bilgiye dayalı karar verme süreçlerinin geliştirilmesini, her düzeyde vatandaşın yönetime katılımının sağlanmasını, kamu yönetiminin elindeki bilgi ve belgeleri kamuoyuyla paylaşmasıyla birlikte şeffaflaşmasını kendisine amaç edinmiştir. E-devletin vatandaş katılımını önemsemesi yerel yönetimlerin halka yakın bir biçimde örgütlenen yapıları ve vatandaşların ihtiyaç ve beklentilerine yönelik doğrudan hizmetler sunmaları nedeniyle önemlidir. İnternet ve ağ teknolojileri yerel yönetimlere özellikle de belediyelere etkin ve saydam bir biçimde karşıllklı etkileşime dayalı çevrim içi hizmetler sunma, halk ve kamu yöneticileri arasındaki iletişimin atması, yönetsel ve güncel bilgilerin halka hızlı bir biçimde iletilmesi gibi olanaklar sunmaktadır. E-belediyecilik, her şeyden önce, yönetim kademelenmesindeki hiyerarşik ve bürokratik yapının kırılmasında önemli bir role sahiptir. E-belediyecilik ile belediye yönetiminin daha şeffaf, hesap verebilir ve demokratik olması sağlanmaktadır. Devletin, halkın ve sivil toplum kuruluşlarının belediyenin faaliyetlerini yakından takip etmeleri mümkün hale gelmektedir. E-belediyecilik uygulamalarının başarısı kent bilgi sistemleri ve coğrafi bilgi sistemlerinin oluşturulması, kullanıcı taleplerine dönük interaktif bir belediye ağ sayfası ve belediyenin mobil hizmetler sunabilme olanaklarıyla yakından ilgilidir. E-belediyecilik, toplu taşıma, ulaşım, su ve kanalizasyon gibi temel kentsel sistemlerin yönetiminde, veri toplanması, sınıflandırılması ve işlenmesi süreçlerinde önemli kolaylıklar sağlamaktadır.

Türkiye'de e-belediyecilik çalışmaları 1989 yılında TODAİE bünyesinde kurulan Yerel Yönetimler Araştırma Merkezinin faaliyetleri ile önem kazanmaya başlamıştır. Bu kapsamda 2001 y1lında yerel yönetimler portalı oluşturulmuştur. Aynı yıl ortaya çıkan Yerel Bilgi Projesi yerel yönetim birimlerinin diğer kamu kurumlarıyla olan ilişkilerini sanal ortama taşımıştır.

Çalışma kapsamında 2014 yerel yönetim sonuçları dikkate alınarak İzmit Belediyesi sınırları dahilinde gerçekleştirilen ankette katılımcıların belediyenin sunmakta olduğu online vezne, e-imar, 
Demirel, D. (2017). The utilization level of the citizens from E-Municipality services: The example of İzmit municipality. International Journal of Social Sciences and Education Research, 3(2), 411-424.

süper hizmet masası, bilgi edinme başvurusu, başkana mektup, İzmek gibi e-hizmetlerden yararlandıkları ve sunulan hizmetleri de büyük bir çoğunlukla başarılı buldukları görülmüștür. Katılımcılar internet vasıtasıyla e-hizmet sunumunun bilişim toplumunun oluşumunu destekleyeceğini, hesap verebilirliği arttırarak demokratik bir yönetsel yapının gelişimine katkıda bulunacağını belirtmişlerdir. Yapılan araştırma sonucunda sunulmakta olan e-hizmetlerden daha çok orta yaş ve üstündeki yaş gruplarının yararlandığı görülmüştür. Gelir düzeyi yüksek grupların e-hizmetlere ilgisinin yüksek olduğu belirlenmiştir. Bu durum gelir düzeyi yetersiz kesimlerin e-belediye hizmetlerinden yararlanmaları için birtakım sosyal politikaların icra edilmesinin gerekliliğine işaret etmektedir. Ebelediye hizmetlerinden genellikle işçi ve serbest meslek grupları yararlanmaktadır. Aktif olarak işgücü piyasasına katılmayanlar e-hizmet almamaktadır. E-belediye hizmetlerinden yararlanma bireysel eğitim düzeyiyle de yakından ilişkilidir. Bireysel eğitim seviyesi arttıkça e-hizmet talebi de artış göstermektedir. Böylece bilgi toplumuna dönüşüm sürecinde e-belediyecilik uygulamalarının başarısını arttırmada eğitimli ve yüksek nitelikli insan gücünün önemi bir kez daha ortaya konmaktadir.

\section{Kaynakça}

Akman ve diğerleri (2013), "City Information Systems as E-Municipality Application in Local Administrations: An Evaluation Over Konya and Kayseri Big Cities Examples", Mediterranean Journal of Social Sciences, Vol.4, No:11, pp.758-762.

Anselmi, Luca and et. al (2002), “The Role of ICTS in the Management of Local Municipalities”, International Symposium on Learning Management and Technology Development in the Information and Internet AgeThe Convergent Paths of Public and Private Organizations, University of Bologna, November.

Bengshir, T. ve A. Akay (2006), "Bir Kamu Politikası Aracı Olarak Coğrafi Bilgi Sistemleri (CBS): Türkiye'de Belediyelerin CBS Uygulamalarının Değerlendirilmesi”, Çağdaş Yerel Yönetimler, 15(1):31-46.

Chidurala Murali and et. al (2001), E-Goverment Best Practices: An Implementation Manuel, Maryland: University of Maryland Robert H. Smith School of Business.

Çelikkol, Ömer (2008), Kamu Yönetiminde E-Devlet Yapılanması ve Türkiye İçin e-devlet Model Önerisi, Süleyman Demirel Üniversitesi ve Sosyal Bilimler Enstitüsü, Yayımlanmamış Yüksek Lisans Tezi, Isparta.

de Ruyter and et. al (2001), "Customer Adaption of e-service: An Experimental Study”, International Journal of Public Sector Management, Vol.12, No.2, pp.184-207.

DPT (2010), Orta Vadeli Program (2011-2013), DPT Yayını, Ankara.

Güler, Birgül Ayman (2001), "Yerel Yönetimler ve Internet”, http: //www.inettr.org.tr/ineteonf7/Sunum/Yerel yönetim.doc, (10.09.2016).

Hazman, Gülsüm Gürler (2005), "Afyonkarahisar Belediyesinde E-Belediye Uygulamaları ve Yerel Farkındal1k”, Afyon Kocatepe Üniversitesi İ̈BF Dergisi, C.7, S.2, ss.65-84.

Henden Burçin ve Rıfkı Henden (2005), "Yerel Yönetimlerin Hizmet Sunumlarındaki Değişim ve E-Belediyecilik", Elektronik Sosyal Bilimler Dergisi, 4 (14): 48-66.

Ho, Kei, Alfred Tat (2002), "Reinventing Local Governments and the E-Government Initiative", Public Administration Review, 62(4), pp.434-444.

Moon, Jae M. and et. al (2014), "The Evolution of Internal IT Applications and e-Government Studies in Public Administration: Research Themes and Methods", Administration\&Society, Vol.46(1), pp.3-36. 
Demirel, D. (2017). Vatandaşların E-Belediyecilik hizmetlerinden yararlanma düzeyi: İzmit belediyesi örneği. International Journal of Social Sciences and Education Research, 3(2), 411-424.

Naralan, Abdullah (2008), “E-devlete Etki Eden Faktörler” Atatürk Üniversitesi SBE Dergisi, Cilt:12, Sayı:2, ss.457-468.

Nohutçu, Ahmet ve Demokaan Demirel (2005), “Türkiye'deki E-Devlet Uygulamaları”, Türk İdare Dergisi, Say1.447, ss.35-58.

O’Neill, M. and et. al (2001), "Quality Evaluation in Online Service Environments”, Managing Service Quality, Vol.2, No.6, pp.402-417.

Polat, Burak ve diğerleri (2013), "E-Transformation of Municipalities and Social Media's Role on e-participation in European e-Municipalities”, Academic Journal of Interdisciplinary Studies, Vol.2, No.9, pp.386392.

Pollitt, Christopher (2011), "Mainstreaming Technological Change in the Study of Public Management", Public Policy and Administration, 26 (4), pp.377-397.

Postac1, Talat ve Aytunç Ayhan (2013), “E-Dönüşümün Kent Yaşamına Etkileri (E-Belediye) ve Yeni Beklentiler”, Anahtar Dergisi, Say1:291, ss.17-19.

Şat, Nur (2008), Demokrasi İçin Bir Araç: E-Belediye, Marmara Üniversitesi SBE Yayımlanmamış Doktora Tezi, İstanbul.

Uçkan, Özgür (2003), E-Devlet, E-Demokrasi ve Türkiye: Kamu Yönetiminin Yeniden Yapılanması için Strateji ve Politikalar-I, Literatür Yayıncılık, İstanbul.

Yargovan, Serkan (2013), Transformation of Administration into e-government: From municipality in İstanbul, Metropolitan Municipality in Turkey, Jönköping University, International Business School, Bachelor's Thesis in Informatics, Sweden.

Yıldırım, Murat (2010), "Kamu Yönetimine Güven: E-Devlet Açısından Bir İnceleme”, Cumhuriyet Üniversitesi İ̈BF Dergisi, C.11, ss.1-19.

Yıldırım, Uğur ve Şerif Öner (2004), "Bilgi Toplumu Sürecinde Yerel Yönetimlerde Eğitim-Bilişim Teknolojilerinden Yararlanma: Türkiye'de E-Belediye Uygulamaları”, The Turkish Online Journal of Educational Technology- TOJET, 3(1): 49-60.

\section{Extended abstract in English}

In the globalizing world, the foundation of the information society constitutes the ability to perform activities and to make quick transactions Efficiency in state administration brings resultsoriented and efficiency in public services. Political reflection of the information society is e-government reforms. The e-government aims to provide public services effectively through information and communication technologies. Along with the e-government, public administration has turned to technical-oriented service policies. Communication between the administration and the citizen has been strengthened by the widespread use of information and communication technologies. E-government has an intermediary role in the participation of citizens in political and administrative decisions. Factors such as computer literacy and economic strength of those who use e-services are crucial to the success of the e-government. It has been found that the development of the e-government is slower in the state countries. Because public institutions that provide egovernment services are bulky. The inadequacies of technical infrastructure and qualified human power prevent the success of the e-government. As an agent of e-government, e-service aims to reach citizen and/or customer satisfaction in order to improve organizational performance. Eservice applications are shaped by citizen demands and are intended to provide quality service 
Demirel, D. (2017). The utilization level of the citizens from E-Municipality services: The example of İzmit municipality. International Journal of Social Sciences and Education Research, 3(2), 411-424.

delivery. E-services are expected to be most successful in local governments due to their proximity to the citizens. There is a dialogue environment between public institutions with e-municipality applications and integration between the institutions is provided. Communication between the municipality and the citizens is strengthening. Administrative activities of the municipality are accelerating. The cost of local services offered is reduced. The reduction of the bureaucratic processes at the local level and the paperwork enable efficiency in resource use. Citizens can obtain information about administrative processes in local governments. The performances of the municipality, revenues, expenditures, strategic plans and annual reports are displayed on the internet. This provides transparency in the public administration. It prevents privacy and corruption practices in public administration. It enhances the citizens' confidence in the practices of local governments. Local democracy ensures that the wishes, complaints and proposals of the local people are evaluated in a fast electronic process.

In the process of e-municipalisation, it is necessary to establish geographical information systems where basic geographical qualities related to the city are included. At the same time the municipalities should design a network page. When a network page is designed, an informationoriented or user-focused approach can be demonstrated. One-stop service provision becomes important in the knowledge-based approach. One-stop service delivery covers topics such as urban budgets, local activity calendar, major tourist attractions, guides, press releases and business opportunities. In the user oriented portal design, the information and services on the network are classified according to the needs of different user groups. Sites based on e-staff presence in the background and user-oriented are evaluated as e-gates. The ease of use of the network page, transparency and reliability are of vital importance. In addition, in the presentation of e-municipality services, it is necessary to provide internet access via mobile communication means. With municipal wireless services, citizens can access online services and information online from their mobile phones or PDAs. In order to achieve success in e-municipality applications, it is necessary to establish performance indicators related to the services provided, to establish an institutional performance management system, to determine strategic internal and external stakeholders. It is also important that e-municipality projects and practices are coordinated with a holistic and knowledge-based approach. Improvement of common infrastructure and services, provision of services in a holistic manner, focus on users' demands and expectations, user satisfaction, privacy of individual information and the importance of information security will increase the success of e-municipality.

The e-municipalization process in Turkey is at a stage of development and is a new phenomenon yet. In 1989, the Local Administrations Research and Training Center was established within the TODAIIE (Turkish Middle East Public Administration Institute). Thus, the Local Net Network, in which all the local administrations in Turkey are gathered, is called as the local government portal. As of 01.01.2001, the portal has been implemented as "yerelnet.org.tr." The Local Information Project prepared by the General Directorate of Local Authorities of the Ministry of Interior have been moved the relations of local government units with other public institutions to the internet environment. The main e-services of Izmit Municipality examined in this study are IZMEK, which provides information about the activities of vocational courses of the municipality, online cashier's desk, e-reconstruction applications, super service desk, and letters to the president. In order to measure the e-service effectiveness of the municipality, a direct survey was applied to 384 people using the random sample method. Survey results were evaluated by taking $\pm 5 \%$ error margin in $95 \%$ confidence interval. SPSS 22.0 program was used in the evaluation of 
Demirel, D. (2017). Vatandaşların E-Belediyecilik hizmetlerinden yararlanma düzeyi: İzmit belediyesi örneği. International Journal of Social Sciences and Education Research, 3(2), 411-424.

the survey results. Frequency and percentage distributions of data are examined. Data were evaluated according to the one-way ANOVA test and the Chi-Square Independence Test. The number of women participating in the survey is higher than that of men. The majority of participants are between the ages of 36-45. Participants generally have a higher level of education and most have an undergraduate degree. In terms of occupation, participants are more in the status of workers. The majority of participants have income levels above 3000£. Participants' levels of utilization of e-services provided by Izmit Municipality are very close to each other. Participants benefit most from the municipality's e- reconstruction and letters to the president. A large majority of respondents indicated that e-services provided by the municipality were successful. Citizens believe that providing e-service from the internet will contribute to the transformation of the informed society, and argue that e-services will provide accountability by providing democratization in municipal administration. The level of education and income of the participants and emunicipality practices are also in an accurate proportion. When the level of education and the level of income decrease; the rate of utilization of e-municipal services also decreases. Most beneficiaries of e-municipal services are middle age group between the ages of 36-45, workers and self-employed groups. The rate of 18-25 age utilization of e-municipal services is lower than other age groups. The 18-25 age group benefits less from e-municipal services than other age groups. 